\title{
A comprehensive, holistic people integration process for mergers and acquisitions
}

\author{
Authors: \\ Rina P. Steynberg ${ }^{1}$ \\ Theo H. Veldsman ${ }^{1}$ \\ Affiliations: \\ ${ }^{1}$ Department of Industrial \\ Psychology and People \\ Management, University of \\ Johannesburg, South Africa \\ Correspondence to: \\ Theo Veldsman \\ Email: \\ theov@uj.ac.za \\ Postal address: \\ PO Box 524, Auckland Park \\ 2006, South Africa \\ Dates: \\ Received: 12 Aug. 2010 \\ Accepted: 22 Nov. 2010 \\ Published: 01 Mar. 2011 \\ How to cite this article: \\ Steynberg, R.P., \& \\ Veldsman, T.H. (2011). A \\ comprehensive, holistic \\ people integration \\ process for mergers \\ and acquisitions. $S A$ \\ Journal of Human \\ Resource Management/ \\ SA Tydskrif vir \\ Menslikehulpbronbestuur \\ 9(1), Art. \#242, 16 pages. \\ doi:10.4102/sajhrm.v9i1.242
}

(C) 2011. The Authors.

Licensee: OpenJournals Publishing. This work is licensed under the Creative Commons

Attribution License.
Orientation: Mergers and Acquisitions (M\&As) are a frequent, alternative strategic growth option to organic growth for organisations. The failure rate of mergers and acquisitions is alarmingly high (70\% plus failures). The people factor is seen as one of the main contributors to this failure.

Research purpose: To develop and validate a comprehensive, holistic model for the people integration process during mergers and acquisitions.

Motivation for the study: The literature on a comprehensive, holistic people integration process for mergers and acquisitions is sparse and fragmented.

Research design, approach and method: A qualitative approach was adopted consisting of a three step process which solicited the views of seasoned M\&A Practioners; these views were compared against the available literature. Finally, practioners were asked to critique the final model from a practice perspective. The utility of the final model was assessed against two mergers and acquisitions case studies.

Main findings: A comprehensive, holistic people integration process model for mergers and acquisitions was developed and validated. However, this model will only significantly enhance mergers and acquisitions value realisation if it is applied from the appropriate vantage point.

Practical/managerial implications: The proposed approach will increase the probability of a successful M\&A people-wise and M\&A value realisation.

Contribution/value add: Theoretically, the development and validation of a M\&A people process integration model; practically, guidelines for successful people integration; organisationally, significantly enhancing the chances of M\&A success; and community wise, the reduction of the negative effects of M\&A failure on communities.

\section{Introduction}

\section{Key focus of the study}

Over the last four decades mergers and acquisitions (M\&As) have become an integral part of the strategic initiatives adopted by organisations in order to make their business grow (Galpin \& Herndon, 2007; Sherman, 1998; Wickramasinghe \& Karunaratne, 2009). The strategic option of M\&As, complementary to the strategic option of organic growth, has thus been firmly established as an attractive business strategy (Schuler \& Jackson, 2001; Veldsman, 2002).

The terms mergers and acquisitions are often confused or used interchangeably. This distinction in meaning may not make much of a difference due to the fact that the result is often seen as two or more companies with separate ownership, now operating under the same roof to achieve shared strategic and/or financial objectives. The nature of the deal, however, may have a strategic, financial, tax and/or cultural impact, to name but a few implications. For the purpose of this study, the terms mergers and acquisitions are used as follows (Schuler \& Jackson, 2001; Sherman, 1998; Veldsman, 2002): a merger refers to the situation where two or more free-standing entities of equal standing become a new entity with the original entities disappearing. An acquisition pertains to the buying of one or more free-standing organisations by another organisation, the buyer, which retains its identity. In the case of mergers, both partners are presumed to play an equal role in the marriage. Partners are of unequal standing in the case of acquisitions.

Why do organisations choose M\&As as a strategic growth option? M\&As offer organisations inter alia the opportunity of seizing competitive advantages flowing from: 
- globalisation (Chapman, 2003; Galpin \& Herndon, 2007; Schuler \& Jackson, 2001; Sherman, 1998; Tanure \& Gonzalez-Duarte, 2007)

- access to new technology and/or resources (Chapman, 2003; Schuler \& Jackson, 2001; Veldsman, 2002)

- economies of scale and cost savings (Chapman, 2003; Galpin \& Herndon, 2007; Schuler \& Jackson, 2001; Veldsman, 2002)

- a wider product and/or service offering (Veldsman, 2002)

- capital investment risk mitigation (Sherman, 1998)

- rapid entry into a (new) market(s) (Chapman, 2003; Galpin \& Herndon, 2007; Schuler \& Jackson, 2001; Sherman, 1998; Tanure \& Gonzalez-Duarte, 2007; Veldsman, 2002) industry consolidation (Galpin \& Herndon, 2007; Sherman, 1998)

- the acquisition of intellectual capital, competencies and talent (Galpin \& Herndon, 2007; Schuler \& Jackson, 2001; Sherman, 1998; Veldsman, 2002)

- dealing with the economic ramifications of political and/ or regualatory changes and other pervasive contextual trends that impact on future prospects of organisational success, such as financial viability (Chapman, 2003; Schuler \& Jackson, 2001; Sherman, 1998).

\section{Background to the study}

Any M\&A is an extremely complex process from the pre-deal planning phase of strategic intent, through start up, integration and sustainability. The ultimate question regarding any M\&A is whether there will be genuine, sustainable value realisation after the M\&A deal. The reported failure rate of M\&As is dismally high (typically estimated to be more than 70\%) (Galpin \& Herndon, 2007; Schuler \& Jackson, 2001). For example, KPMG has reported that within 18 months of deal closure, $80 \%$ of large capital transactions failed to meet M\&A objectives and shareholder expectations (Kelly \& Cook, 1999). Only $17 \%$ created shareholder value (Schuler \& Jackson, 2001). A Watson Wyatt survey of 1000 organisations found that at most $46 \%$ met their cost reduction goals, less than $33 \%$ attained their profit goals after the M\&A and $64 \%$ of the time the M\&A did not realise the expected benefits (Boglarsky, 2005).

Several reasons are offered for M\&A failure (Galpin \& Herndon, 2007). A culture clash between the integrating organisations is consistently cited as one of the top ten reasons for M\&A failure, especially as the dominant reason for failure during the post-deal integration phase (Baughn \& Finzel, 2009; Bekkier, Bogardus \& Oldman, 2001; BijlsmaFrankema, 2001; Boglarsky, 2005; Galpin \& Herndon, 2007; Schuler \& Jackson, 2001). If culture clashes are one of the top ten reasons for M\&As not producing the expected shareholder value, it clearly accentuates the complexities of people integration during M\&As.

Why are the people issues ignored if they play such a critical role in the success (or failure) of M\&As? Some of the reasons for ignoring people issues are (Schuler \& Jackson, 2001):
- an overemphasis of other aspects such as the financial side of the deal

- the absence of a people integration framework or model to enable the people integration process

- the belief that the people issues are too soft and intangible to deal with, a lack of awareness and/or consensus that the people issues are important

- the absence of an assertive custodian or sponsor in the affected organisations for the people side of the M\&A.

During the height of the economic boom in 2007, according to the annual Ernst and Young South Africa M\&A report, M\&A deals to the value of R513 753 million were concluded in South Africa (Weaver, Keys \& Tayser, 2008). During that time there were 17.23 million economically active people in South Africa. South Africa's GDP during the corresponding period was R2 016 trillion. The 2007 M\&A deals as a percentage of GDP in that year amounts to $0.029 \%$, implying that about $0.03 \%$ of South Africa's economically active population was affected by such deals. If one assumes that within the South African context, each of these working people had four dependents, one can conclude that M\&A activities during 2007 could have impacted on 4.33 million people in South Africa, either directly or through their families. This figure makes up $9 \%$ of the South African population, assuming there were about 48 million South Africans at the time. The corresponding figure of people affected in 2009 during the economic downturn, with a low value of M\&A deals at $0.01 \%$ of GDP, would imply that an estimated 1.49 million people could have been affected (Tayser, 2010).

The effectiveness or not of the M\&A people integration process thus has a direct bearing on the trauma experienced by people during an M\&A, even beyond the persons directly affected, resulting in wide spread emotions such as uncertainty, fear, aggression and depression (Ing, 2000). More M\&A activity is forecast for South Africa due to the foreign interest in South African assets, firm commodity prices and the relative stability of the Rand (Gillingham, 2006; The Economist, 2006). If M\&As fail frequently (or only succeed partially), as has been consistently reported, the emotional trauma associated with M\&As would be widespread and also affect the national psyche of a country beyond the boundaries of the organisations involved in the M\&A.

\section{Problem definition and research objectives}

Considering the perenial presence of M\&As as a strategic option for organisations to grow, the expected increase in M\&A deals, the stakeholder value which is destroyed if a deal fails, the effect of M\&As on people within the organations affected and M\&As' impact on the national psyche of a country, a sound model for navigating people integration during M\&As is a dire need, especially considering the paucity of the literature dealing with this matter. Such a model would contribute to:

- enhancing the probability of successful M\&As

- increasing the value realisation for shareholders

- enabling a more change resilient organisational members and national psyche as far as the impact of M\&As is concerned.

The problem statement informing the study was the development of a comprehensive, holistic people integration 
process model for people integration during M\&As that can be used to enhance the probability of successful M\&As peoplewise.

The following research objectives were set:

- to develop a model (called Model P) based on best/leading practice, where the building blocks for the intended model are collected from seasoned experts and practitioners in the M\&A field.

- to develop a theoretical model (called Model T) based on a comprehensive review of the M\&A literature study, reflecting the latest think about M\&As.

- to verify Model $\mathrm{T}$ with experts and practitioners in the M\&A field.

- to integrate Model P (the practice) and Model T (the theory), and then to verify the integrated model again with experts and practioners in order to propose a final people process integration model (called Model TP).

- to explore the practical application possibilities of Model TP by applying the model as a diagnostic framework to two real life case studies.

\section{Research Design \\ Research approach}

The approach was qualitative and explorative in nature. The researchers aspired to describe the phenomenon, in this case M\&As, from the experience of respondents who have been exposed to and/or involved in M\&As and the meaning they ascribe to this experience (Schurinck, 2003). In turn, these experiences were compared against the available M\&A literature on the people process integration during M\&As.

\section{Population, sample and sampling}

The population consisted of seasoned experts and practitioners in the M\&A field who have had at least six years' experience in the field. Cases that contained the most characteristic, representative, or typical attributes of the population were included in the research sample. This type of sample is based entirely on the judgment of the researcher and is known as purposive sampling (De Vos, Strydom, Fouché \& Delport, 2002). The choice of respondents was driven by the study's problem statement and research objectives and not by a concern for representativeness. Miles and Huberman (1994) describe this approach as theory based sampling.

\section{Research Method}

\section{Data collection methods, sampling and strategies to ensure} quality data

Data were collected from respondents in the M\&A field on three different occasions. Firstly, data were collected in one-onone interviews $(N=10)$ for the purpose of developing Model P. The following guidelines were followed to ensure quality interviews (Welman \& Kruger, 1999):

- the purpose of the interview was explained to the respondent in advance to ensure focus and co-operation

- the uniqueness and contribution of different respondents were acknowledged, and anonymity was ensured
- the interview was facilitated objectively without the opinion of the researchers expressed on any matter raised.

Firstly, the interviews were typed, transcribed and then analysed to identify building blocks for a practice model. The findings from the M\&A practice interviews were used to build the practice model (Model P).

Secondly, the theory model (Model T), built from the existing literature, was distributed amongst respondents $(N=50)$, again seasoned M\&A experts and practioners, in a questionnaire format, to verify this model. The questionnaire contained all the phases and building blocks with their inter-relationships and definitions where appropriate. Respondents were asked in the questionnare to confirm the M\&A phases and building blocks, as well as their interrelationships and sequencing as distilled from the literature. These findings were used to enhance the literature-based Model T and arrive at Model TP.

Thirdly, in order to explore the practical utility and validity of the finally proposed people integration process model (Model TP), the model was shared in one-on-one interviews with two respondents involved in two actual M\&A cases. The respondents were requested to apply Model TP as a diagnostic framework to the two different M\&A case studies in order to assess the proposed model's usefulness. In the first case study, a post mortem application was conducted on a historical M\&A. In the second case study, the application was to a project plan, designed for an M\&A which was currently underway at the time.

\section{Recording of data and data analysis}

A qualitative data analysis process, as described by Neuman (2003), was followed. In building sequentially, firstly, the practice model (Model P) and, secondly, the theory model (Model T), the same process was followed:

1. The initial field notes, transcribed interviews and handout documents were integrated into a single data set. Data were roughly arranged from earlier to later and from simple to complex.

2. After the data had been sorted, open coding was applied to identify building blocks for the models. The researcher worked through the data searching for critical themes which were then recorded. The themes identified were regarded as the emerging building blocks for the models.

3. Axial coding was applied to organise and cluster themes. During this step the focus was on interactions, relationships, sequencing and dynamics between building blocks.

4. Selective coding was applied next to scan the data and previous codes for the purpose of identifying more themes and looking for comparisons and contrasts in the data (Babbie \& Babbie, 1992).

5. Pattern coding was then used to start mapping the building blocks in a model. This step ensured that data were mapped and relationships illustrated. The outcomes of the data analyses for Models T and P respectively were presented in the form of graphic illustrations of a people integration process. 
After the theoretical model had been built, it was verified by experts and practitioners in the M\&A field as outlined earlier. A successive approximation data analysis technique was applied, using the verification findings from the field work to enrich Model T. Successive approximation is a process whereby the data analysis begins with research question(s) and a framework of assumptions and concepts (in this case, the people process integration model). Data were analysed by probing and questioning to see how well the concepts fitted the evidence. Abstracting from the evidence, new themes (or building blocks) were created or adjusted to better fit the evidence.

Additional evidence was collected to address unresolved issues and the analysis was then started all over again. At one stage the evidence and the theory shaped each other to arrive at a final conclusion. This process is called successive approximation because the modified concepts and the model approximated the full evidence, and were modified over and over to become successively more accurate (Neuman, 2003). Models $\mathrm{T}$ and $\mathrm{P}$ and the verification findings were integrated to arrive at Model TP.

The last step in the data analysis process was applying Model $\mathrm{TP}$ in practice in an exploratory fashion as a diagnostic framework to two case studies. In both case studies the narrative data analysis technique was applied (Neuman, 2003), following the guidelines provided by Eisenhardt (1989) in building theory from case studies. In this process, data were assembled into a descriptive story of what occurred (i.e. the historical case study) and what will occur (i.e. the project plan). The respondents were asked to apply Model TP to their case studies in order to assess its applicability. Their perspectives with regard to the application possibilities of Model TP were narrated as part of their stories.

Acccurately capturing the experiences by respondents and correctly reporting the findings from the literature ensures a high degree of validity. The validity was increased by successive instances of consulting with experts and practitioners in the M\&A field. Protecting the confidentiality of respondents and organisations ensured high ethical standards in this study.

\section{Model mapping}

The final intended outcome of this study was a mapped, expert-verified model: Model TP. The concept 'model' therefore needed to be defined. For the purpose of this study, the definition of Mouton (1996) was adopted:

A model is an attempt to represent the dynamic aspects of a phenomenon by illustrating the relationships between its elements in a simplified form. A model is only a partial representation of a given phenomenon.

(Mouton 1996, p. 198)

The criteria of an adequate model needed to be defined and the final model had to be evaluated against these criteria. The following criteria were considered (Box, Hunter \& Hunter, 1978; Meredith, Wong, Woodhead \& Wortman, 1985; Morgan \& Morris, 1999; Mouton, 1996):

- The model must be simple, though inclusive enough to make sense.
- The model must describe, explain and prescribe the phenonmenon studied.

- The model must cover both theory and practice.

- All the necessary ingredients of the model must be included, such as its elements, relationships and the dynamics making up the model.

- There must be both constant and variable elements within the model.

- The model must have application value, which would suggest practical value.

Throughout the research process of first generating Model P, then Model T and finally Model TP, these criteria were used as refence guidelines in order to arrive at good models.

\section{Findings}

\section{Model $\mathrm{P}$ reflecting best/leading merger and acquisition practice}

Model $\mathrm{P}$, resulting from interviews with seasoned experts and practitioners in the M\&A field, is given in Figure 1. Given the importance of understanding the full compexity and multidimensionality of the M\&A process people-wise and in order to set the scene for Model PT, the complete model is given (and not merely a simplified version).

As shown in Figure 1, Model P consists of four phases, three levels and building blocks, all categorised into different phases and layers. The phases and building blocks were organised in a linear, cause-and-effect manner.

The M\&A process consists of four phases, namely:

- Phase 1: Strategic intent

- Phase 2: Pre-start

- Phase 3: Integration/transition

- Phase 4: Sustained renewal.

The building blocks (or elements) are illustrated in Figure 1 on three different levels, namely:

- M\&A process management

- transactional people themes during M\&A

- transformational people themes during M\&A.

The reason for the M\&A determines the choice of M\&A as a growth strategy. The profile of the leaders and the organisational capabilities influence the choice and the strategic intent.

A clear M\&A overall integration process exists, described in a linear manner: from strategic intent, through due diligence, memorandum of agreement, deal announcement, appointment of the integration team, decision on the degree of integration and integration strategy, integration outcomes, tracking, post mortem, continuous improvement, to celebration of success.

The people integration consists of the following building blocks:

- vision, mission and strategy

- leadership and culture (i.e. expected new behaviour)

- expectations, goals, values and team integration

- organisational structure, jobs and positions

- competencies and the appointment of people 


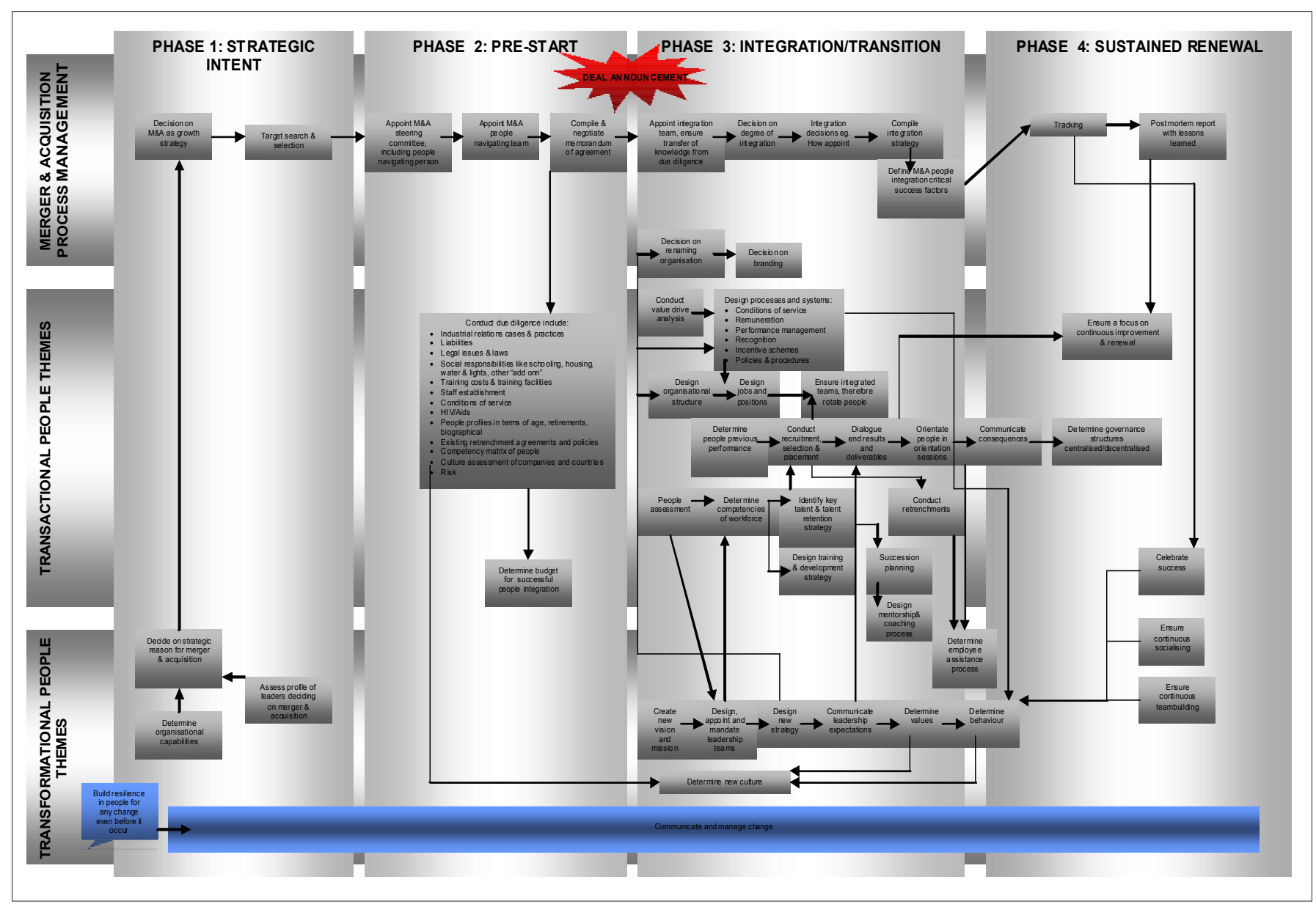

FIGURE 1: Model P reflecting best/leading M\&A as sourced from practice.

- succession planning, talent retention, mentorship, coaching, training and development

- the alignment of people systems, processes, policies and procedures.

All these people building blocks are categorised either under transactional or transformational people themes.

\section{Model TP, reflecting the literature and as validated by seasoned mergers and acquisions practitioners and experts}

Model T, as sourced from the M\&A literature, was developed based on:

- M\&A practice models (e.g. General Electric, Cisco) (e.g. Evans, Pucik \& Barsoux, 2002; O’Reilly \& Pfeffer, 2000)

- reviews of best practice (e.g. Corporate Leadership Council, 1997)

- high level/partial M\&A inegration frameworks (e.g. Schuler \& Jackson, 2001; Veldsman, 2002)

- $\quad$ articles addressing specific aspects of M\&A (e.g. Schuler \& Jackson, 2001)

- general people management and change theories (e.g. Burke \& Litwin in French \& Bell, 1999).

The result of integrating the practice model (Model P) and the theory model (Model T) and the verification findings resulting from M\&A practitioners and experts assessing Model T (not given here because of space constraints, but more importantly for the reasons offered under the Discussion and Interpretation Section), was a final proposed people integration process model (Model TP). Model TP is shown in Figure 2.

According to Figure 2, Model TP consists of various elements, categorised into layers. The respective elements and layers are:

(i) A core denominator that forms the centre around which all of the other processes revolve (see Figure 2). The core directs and guides the M\&A process. The core denominator is made up of:

(1) the strategic intent the organisation has for $M \& A$ as a strategic growth option

(2) the M\&A integration strategy.

The strategic intent forms the reason for pursuing M\&As. The business may take a strategic decision to grow and M\&As may be the appropriate strategy through which the organisation wishes to pursue that growth (McNamara, 1999). Businesses may have different reasons why they choose M\&As as a growth strategy. These reasons may include integration in order to share and optimise resources, geographical expansion, new technology and new markets (see also the Introduction of this article). The strategic intent for the M\&A has implications for the execution of the deal as well as for the people integration (Evans, Pucik \& Barsoux, 2002; Kurtz \& Snowden, 2003; Rock, Rock \& Sikora, 1994). 


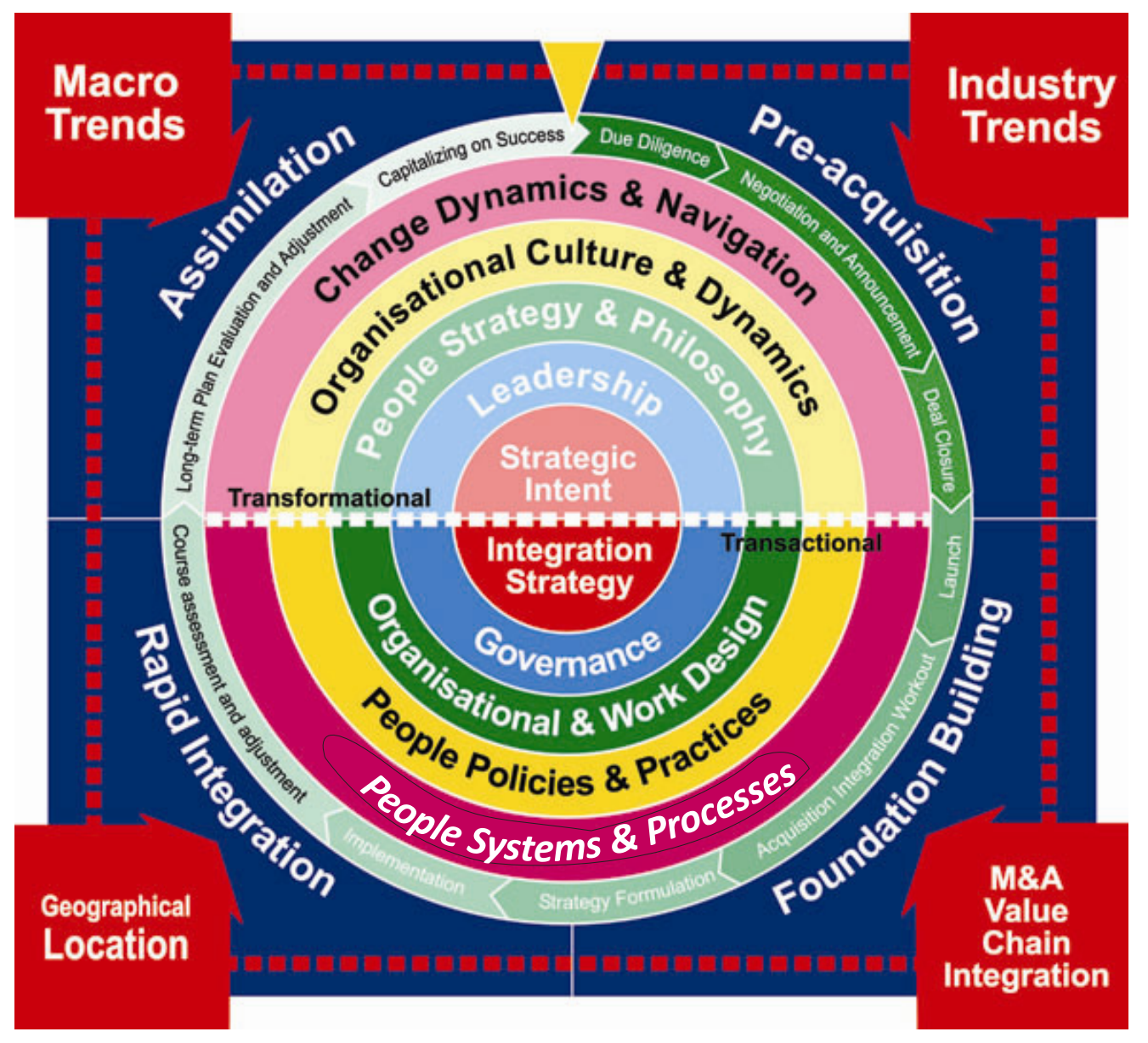

FIGURE 2: A comprehensive, holistic people integration process model (Model TP).

The Strategic Intent also impacts on the MEA integration strategy which is influenced by the degree of integration desired (Galpin \& Herndon, 2007; Kale, Singh \& Raman, 2009; Schuler \& Jackson, 2001; Tanure \& Gonzalez-Duarte, 2007). There is a significant impact difference between moderate integration versus complete integration desired (Galpin \& Herndon, 2007; Kale, Singh \& Raman, 2009; Nadler \& Limpert, 1992, in Veldsman, 2002; Tanure \& Gonzalez-Duarte, 2007). The degree of integration should first be understood before the M\&A integration strategy is designed. The core denominator impacts on the rest of the M\&A process and therefore also determines the necessary type of people integration. The integation strategy must be supported and enabled by an efficient and effective M\&A governance structure and process to direct and guide the integration process (Galpin \& Herndon, 2007; Schuler \& Jackson, 2001).

(ii) The layers around the core denominator are divided into two halves. The upper half contains the more transformational elements and the lower half the more transactional elements of the people integration process (see Figure 2). A search of the literature with regard to existing people models from the general people field uncovered the Burke-Litwin model of organisational change as the most comprehensive people framework (French \& Bell, 1999). This framework was used to inform the perspective adopted regarding the M\&A people process integration elements and their categorisation. During transactional change, some of the features of the organisation change, but the fundamental nature of the organisation remains the same. Transactional changes include, for example, changing structures, practices and systems. These changes cause changes in work climate, which in turn impact on motivation and performance. During transformational change the vision, mission, strategy and leadership styles of the organisation change fundamentally. In other words, the essentail identity and positioning of the organisation is affected. Transformational change causes organisational culture and transactional change, which in turn impact on performance (French \& Bell, 1999). The transformational elements included in Model TP impact directly on the transactional elements in the same layer of the model and vice versa.

(iii) The transformational elements in the upper half of the model depicted in Figure 2 consist of leadership, people strategy and philosophy, organisational culture and organisational dynamics. The change dynamics and navigation layer are present in both the transformational and the transactional halves. Based on the literature reviewed, the transformational elements can be defined as follows:

- Leadership: 'How direction is given in the organisation and people mobilised and inspired around the chosen direction' (Veldsman, 2002, p. 6), or shifting and aligning 
the thinking of people and, in the process, transforming and enhancing performance (Rock, 2006). During the M\&A processes, the leadership from the organisations concerned need to be aligned with regard to their views on the intent of the M\&A, the degree of integration, the future picture of the new entity and the M\&A integrating principles to be followed (Boglarsky, 2005; Galpin \& Herndon, 2007; Marks \& Mirvis, 1998; Tanure \& GonzalezDuarte, 2007). Many M\&A case studies demonstrate that M\&A value is not realised because the leaders of one organisation represented a threat to the leaders of the other organisation. These situations frequently culminate in the resignation of very talented leaders (Grundy, 2003; Hitt, Harrison \& Ireland, 2001; Kanter, 2003), as well as a toxic organisational culture of mistrust and conflict. The retention of key leaders and people in the new entity is one of the most important M\&A challenges. The people integration process should include leadership processes such as leadership profiling and assessment, determining the leadership's current/future styles and practices, the ongoing and widespread communication of the chosen leadership philosophy for and approach to the new entity, as well as leadership visibility during the M\&A process, to name but a few.

- People strategy and philosophy: 'The framework of intangible and untestable assumptions, guiding and directing decisions regarding the management of people within the organisation. The philosophy creates and sustains a certain reality regarding people and how they need to be treated' (Veldsman, 2002, p. 263). Part of this element will be the intended people philosophy and the people strategy of the new entity, as well as the existence and mandate of the to-be-formed Human Resources Function. For example, if the M\&A process starts with all organisational functions being represented in directing and guiding the M\&A process except for the Human Resources Practioners, it sends a clear message to the people regarding their importance during the process (Antila \& Kakkonen, 2008; Tanure \& Gonzalez-Duarte, 2007). The following aspects signal that people integration is a serious matter for the integrating organisations: a substantive budget for people integration initiatives, the expressed need for a fully fledged Human Resources Function in the new entity, a clear mandate for the Human Resources Function and the visible, explicit inclusion of people elements within the set visions and strategies (Antila, 2006; Antila \& Kakkonen, 2008). Cisco Systems, for example, always declare in their M\&A deal announcement the importance of people and talent retention (O'Reilly \& Pfeffer, 2000).

- Organisational culture: Shein(1986)describesculture using a three-level cultural model consisting of the following: artifacts (such as the architecture, rituals and visible things in the organisations), espoused values (such as the documented vision and values) and the basic underlying assumptions that truly drive the organisation (Deeprose, 2003). As mentioned in the introduction, organisational culture clashes are one of the primary reasons why organisations fail to deliver on M\&A expectations. Culture integration is therefore one of the major challenges during people integration (Appelbaum, Gandell, Yortis, Proper
\& Jobin, 2000; Bijlsma-Frankema, 2001; Deans, Kroegler \& Zeisel, 2003; Devoge \& Shiraki, 2000; Galpin \& Herndon, 2007). Part of the culture integration would be to identify the current cultures (this process needs to take place as early as possible in the due diligence phase), determine cultural differences and compatibility, profile the culture of the new entity, assess the gap between each organisation and the newly visualised culture and implement interventions to enable the organisations to embed the new desired culture in a sustainable fashion (Appelbaum, Gandell, Yortis, Proper \& Jobin, 2000; Bijlsma-Frankema, 2001; Towers Perrin Consulting, 2000).

- Organisational dynamics: The culture dynamics represent 'how people relate to and interact with each other' (Veldsman, 2002, p. 60). This equates to the manifestation of the underlying assumptions, beliefs, values and norms contained in the culture in the 'atmosphere' infusing the organisation. All of these direct and guide behaviour. Behaviour again impacts on people, which in turn leads to team and organisational dynamics. Organisational dynamics manifests itself in relationships, interpersonal networks, politics and rumours (Appelbaum, Gandell, Yortis, Proper \& Jobin, 2000; Bijlsma-Frankema, 2001; Human Synergistics, 2000).

- Change dynamics and navigation: This encompasses the conversion of the 'what is' state into the 'what should be' (or vision) state. Simultaneously, the 'in between' state has to be traversed (Kotter, 1996; Veldsman, 2002). M\&As have a psychological impact on people. Organisational pathologies such as secrecy, blame, isolation, avoidance, passivity, aggression and feelings of helplessness and worthlessness most often emerge during the 'in between' state (Appelbaum, Gandell, Yortis, Proper \& Jobin, 2000; Appelbaum, Gandell, Shapiro, Belisle \& Hoeven, 2000; Galpin \& Herndon, 2007; Kanter, 2003; Veldsman, 2002; Wickramasinghe \& Karunaratne, 2009). In the literature this phenomenon is described as the 'merger syndrome' (Marks \& Mirvis, 1998). M\&As sometimes cause retrenchments and for the people staying behind the typical 'survivor guilt' results in feelings of depression and loss (Czander, 1993; Interchange International, 2001; Marks \& Mirvis, 1998). Pritchett (1996) outlines stages in the grieving process of people experiencing M\&As. These stages include shock and numbness, suffering and resolution. Each M\&A stage should be managed in such a way as to facilitate the healing of people. Few people professionals are experts in interpreting and dealing with the deeper psychodynamics of people in the workplace (Cilliers \& Koortzen, 2000). Applying any people integration process model without understanding the deeper psychodynamics of people as part of the change navigation might cause the pathologies described earlier to be manifested.

Seo and Hill (2005) proposed an integrative framework within which six theories are espoused to explain people problems and issues during the different phases of M\&A. The six theoretical themes are:

1. anxiety theory

2. social identity theory 
3. acculturation theory

4. role conflict theory

5. job characteristics theory

6. organisational justice theory.

The intensity of emotional responses as viewed within the frameworks of these respective theoretical themes differs according to the M\&A phase.

Change navigation's aim is to enable a constructive and healthy psychological journey and psycho-social dynamics of people during M\&As (Firth, 2000; Schuler \& Jackson, 2001; Snowden, 2003; Veldsman, 2002). A critical success factor of this process is effective, ongoing communication (Appelbaum, Gandell, Yortis, Proper \& Jobin, 2000; Galpin \& Herndon, 2007; Schuler \& Jackson, 2001). Change navigation is about changing the existing patterns of behaviour and inducing new ones that fit the new entity. By facilitating a real shift in the organisational culture and dynamics, behaviour will change (Rock, 2006; Senge, 1990). In changing behaviour, one is likely to see a shift in the organisational culture and performance (Vinassa, 2003).

(iv) The transactional elements, given in the lower half of the model (see Figure 2), consist of governance, organisational and work design, people policies and practices, people systems and processes, as well as the transactional part of organisational change and dynamics (the 'management' part of change navigation) (discussed already). The transactional elements of the people integration process can be described as follows:

- Governance: 'The extent and degree of empowerment and autonomy awarded to people in exercising their responsibility and authority' (Veldsman, 2002, p. 6). The governance structure of the organisation will also reflect the philosophy of the organisation with regard to business ethics (West \& Jones, 1997). The kind of governance structures in an organisation is determined by the kind of leadership philosophy and leadership style. Governance includes the independent auditing of practices followed in the organisation, the delegation of authority, budget control and the tracking of performance.

- Organisational and work design: 'The architecture or ways in which resources are structured to deliver value' (Veldsman, 2002, p. 6). This includes the design, shape, structures, roles and the distribution of responsibilities across the organisation. Decisions have to be made regarding the organisational design (or achitecture) of the new entity (Galpin \& Herndon, 2007; Schuler \& Jackson, 2001). The extent of organisational and work design is influenced directly by the desired degree of M\&A integration. The impact on the organisational and work design is significantly different for a complete integration versus that of a loosely coupled integration. Organisational restructuring, as an inherent part of the M\&A process, impacts on people with regard to retrenchments, as well as on the new skills and competencies needed for the redesigned or newly created jobs. The organisational and work design integration layer would therefore include activities such as retrenchment negotiations, competency assessments, talent retention, selection and placement, training and career guidance and mentoring, to name but a few (Corporate Executive Board, 2000; Corporate Leadership Council, 1997; 1999; Galpin \& Herndon, 2007; O’Reilly \& Pfeffer, 2000).

- People policies and practices: 'The ways of doing, which are the concrete expression of the abstract people philosophy. Practices pertain to the respective activities contained in the people management workflow' (Veldsman, 2002, p. 265). People policies and practices include compliance with labour legislation, people contracts, stakeholder engagement practices and all other policies concerning people (Galpin \& Herndon, 2007; Schuler \& Jackson, 2001; Tanure \& Gonzalez-Duarte, 2007).

- People systems and processes: During integration, decisions need to be made about what systems and processes are appropriate for the new entity. Most of the time, organisations believe their systems are the best. Aligning and/or choosing between systems and processes can therefore cause severe integration conflicts (Corporate Leadership Council 1997, 1999; Haspeslagh \& Jemison, 1991).

(v) The people integration process takes place within the overall $M E A$ process. The overall M\&A process is characterised by different M\&A phases. These phases also shape and drive the people integration process. Different people issues will emerge during different M\&A phases and these need to be managed accordingly. The phases and sub-phases are illustrated in Figure 2 as an outer layer around the people integration layers. The four M\&A phases are the pre-deal, the foundation building, the physical integration and the assimilation phase (e.g. Galpin \& Herndon, 2007; Schuler \& Jackson, 2001):

- Pre-deal phase: The business strategy drives the deal and is therefore seen as the first sub-phase, followed by due diligence, the integration business case, negotiation and deal announcement and deal closure (Evans, Pucik \& Barsoux, 2002; Galpin \& Herndon, 2007; Greiner \& Poulfelt, 2005; Schuler \& Jackson, 2001). Due diligence is a process concerned with legal implications, risk exposure, finances, strategic and people policy review, contractual relationships, operating history, business states and culture (Galpin \& Herndon, 2007; Sarlitto \& Roman, 2006; Sherman, 1998). Often, the people factor is ignored during the due diligence, for example, no culture due dilligence is done, with severe consequences during the integration phase (Schuler \& Jackson, 2001). The due diligence provides information to compile the strategic integration business case. Part of the integration business case is to determine whether the factors driving the deal and making it attractive to the parties involved are real. It is also a process of defining the deal expectations against which the deal's success will be measured at a later stage. The perceived value creation is determined and defined in this sub-phase (Hitt, Harrison \& Ireland, 2000). After the integration business case is defined, the M\&A process will proceed into final negotiations, deal announcement and deal closure.

- Foundation building phase: This phase includes the launch of the new entity, integration planning and workout and new/revised strategy formulation. This phase includes 
inter alia activities such as branding the new entity and aligning leaders around a new vision, mission and values. This is also the perfect opportunity to have sessions with teams and individuals to start the dialogue regarding the new vision and culture (Marks \& Mirvis, 1998). A lack of integration planning was found in $80 \%$ of the M\&As that underperformed (Schuler \& Jackson, 2001).

- Physical integration: This phase consists of the sub-phases implementation and ongoing modification and adjustment. Physical integration is characterised by the physical implementation of the integration strategy and a new vision at the fastest possible speed, the typical 90-120 days basic integration of the entities concerned (Evans, Pucik \& Barsoux, 2002; Galpin \& Herndon, 2007; Schuler \& Jackson, 2001). If this phase is well implemented, it will significantly enhance the chances of value realisation. When poor integration occurs, it has been found that leadership attrition soars to $47 \%$ within 3 years, productivity drops by $50 \%$, employee satisfaction decreases by $14 \%$ and $80 \%$ of the people feel that the leadership cares more about the financial implications or the quality of products (Schuler \& Jackson, 2001).

- Assimilation: This phase consists of the sub-phases longterm plan evaluation and embedding and capitalising on success. Hatton (Smythe Doward Lambert, 1999) is of the opinion that:

After the new entity is in place, the change has just begun. After the new vision is set, it is now all about delivering on the promise and putting vision into reality.

(Smythe Doward Lambert, 1999, p. 3)

In this phase the success of the M\&A is measured against the value creation expectations set in the integration business case. This phase includes ongoing change, continuous improvement and sustained renewal. The new entity starts to create value and new strategies are designed to sustain success and continuously improve performance (Greiner \& Poulfelt, 2005).

A M\&A integration process measurement model to monitor and track progress is essentail to steering and guiding the overall process. Such a model must also include people metrics (Boglarsky, 2005; Galpin \& Herndon, 2007; Kummer, 2008).

(vi)Four contextual forces impact on the people integration process, given in the outer frame of Figure 2. These forces will affect the probability of a successful people integration. The more information is available, or the more informed positions are taken with respect to these forces and the more preplanning regarding these forces takes place, the higher the possibility of a successful people integration. The four forces entail:

- Macro trends: These trends can be described in terms of the amount of uncertainty, present or expected, in the social, political, economical, ecological and technological spheres. As and when a M\&A crosses a national boundary and occurs in the international arena, this uncertainty further increases (see the discussion on geographical location below). Not all factors that influence the success of people integration during an M\&A process are under the control of the organisation itself. Changing economic conditions, for example, may introduce unforeseen dynamics in employment conditions and client retention that could not have been anticipated. Economic conditions can influence exchange rates, interest rates and product/service prices. This might result in the delay of the intended M\&A, which in turn may impact detrimentally on people. The political climate may also have a strong influence on M\&A activity. For example, the sanctions against South African before 1994 impacted negatively on M\&A activity in the country. This resulted in companies closing down. In contrast, today the option exists for South African organisations to merge and acquire internationally (Mittner, 2006). The current forecast for South Africa is an increase in international M\&A activity due to foreign interest in the country, firm commodity prices, the relative stability of the rand, as well as a generally stable political and economy environment (Gillingham, 2006). Or the political interference by government into an intended M\&A because it is believed that the M\&A is not in the best interest of the country.

- Industry trends and customer reaction: The reaction of customers to an M\&A announcement is a critical challenge which has to be managed pro-actively. The industry of the integrating organisations may be undergoing drastic, unexpected change due to, for example, competitor activities, union activities, shifting consumer expectations, regulatory/legislative changes and Competition Board decisions (Visser, 2006). All of these factors can affect the success of the people integration. Sometimes, neither due diligence nor risk mitigation could have foreseen or prevented these occurrences. There is, however, also the possibility that the integrating organisations blatantly ignore external warning signs (Epstein, 2004).

- Geographical location: M\&As across country boundaries have become much more common and frequent (Antila, 2006; Zou \& Simpson, 2008). At present, M\&A's account for the biggest bulk of foreign direct investment by far (over $80 \%$ ), consequently becoming the biggest factor in the integration of the world's economies (Chapman, 2003). Expanding international opportunities will result in an increase in cross-border M\&As (GIBS, 2006). There is a general view that international M\&As are more difficult than national ones. Angwin and Savill (1997) found that countries with very different cultures would identify each other as particularly difficult areas for M\&As. International M\&As are a challenge with regard to differences in laws, economic regulations, financial practices, people practices and national cultures (Child, Faulkner \& Pitkethly, 2001). Other people challenges with regard to geographic location are, for example, rotating people to distant places, rural villages and desert areas.

- M\&A value chain integration: The main reason for any M\&A is to create value for stakeholders. The success of the M\&A will be determined by how effective and efficient the organisations are integrated and the amount of synergy created through this integration to enable value realisation (Galpin \& Herndon, 2007; Hitt, Harrison \& Ireland, 2000; Tanure \& Gonzalez-Duarte, 2007). Hitt, Harrison and Ireland (2001 p. 85) define synergy as 'the ability of two or more organisations to create more value working together 
than they were able to create operating separately.' Only half of the senior executives polled in an Accenture/ Economist Intelligence Unit survey believed that their companies had realised the revenue synergies they had expected from their M\&As. Only 45\% indicated that the cost synergies that were achieved were less than they had expected (Ficery, Herd \& Pursche, 2007). To create synergy, which in turn results in value realisation, every process phase within the M\&A value chain should be aligned. The people integration process therefore needs to be aligned with the overall M\&A value chain process. The challenge lies in aligning and integrating functions such as people, organisational culture, operations, finance, marketing and purchasing to create synergy and value (Ficery, Herd \& Pursche, 2007).

- Operating principles: Overall, Model TP has been put together in an organic, systemic manner, as reflected in Figure 2. The following proposed operating principles apply to the model in lieu of its organic, systemic nature:

- Clockwise movement: The M\&A process moves clockwise through the phases from Pre-deal, Foundation building, through Physical Integration, to Assimilation.

- Interconnectivity: All the elements (or building blocks) are interconnected. A change in one element will have a ripple effect on all the other elements in the people integration process. In other words, what is decided with respect to a given element directly or indirectly affects all the other elements. A domino, snowballing dynamic thus exists across the M\&A landscape, as depicted by Model TP: an earlier event/action/decision in the process will impact, quite possibly in a mutplier manner, on later events/ actions/decisions.

- Cascading: The model has a cascading, sequential nature. There is a natural order in which to address the layers, namely from the 'inside out'. The core creates the context for the next layer and that layer in turn creates the context for the next layer and so forth. A former layer thus forms the foundation for a later layer.

- Fit and alignment: There needs to be a good fit and alignment between all the elements content wise in order to create M\&A synergy.

- Dynamic tension: There is dynamic tension between the transactional and transformational elements. Both sets of elements need to be in balance. 'And' and not 'EitherOr', resolutions need to be sought. In most instances, the transformational element in a given layer will influence the transactional element in the same layer and vice versa.

\section{Comparing the practice (Model P) and the validated theory model (Model TP)}

In comparing the theoretical model (Model TP) (see Figure 2) with the model from practice (Model P) (see Figure 1), three conclusions can be drawn:

- Both models suggest similar people elements that need to be in place to ensure successful people integration.

- The organic, systemic design of the theory model, Model $\mathrm{T}$, was more preferred by respondents because they felt that it illustrated the integration process in a truer manner. In contrast, the practice model is based on a linear model design (see Figure 1).
- The operating principles of the practice model suggest a cause and effect relationship between some of the elements, whilst the operating principles of the theory model suggest the interconnectedness of all of the people elements. The verification findings indicated that respondents preferred the organic, systemic model with its commensurate operating principles.

In essence, there were no major differences between the practice and the theory model in terms of elements and building blocks, except in the overall model design. The verification process of Model $\mathrm{T}$ also did not reveal any significant changes based on the input by the practitioners (hence the reason for not showing Model $\mathrm{T}$ in the article). Models $\mathrm{T}$ and $\mathrm{P}$ were therefore integrated into Model TP (as given in Figure 2) retaining the organic, systemic design of the model.

\section{Exploring the application of Model TP in practice}

As the final step in the research process, the application value and validity of the comprehensive, holistic people integration process model (i.e. Model TP, given in Figure 2) was explored by means of two case studies. In both case studies individuals responsible for people integration during M\&As were asked to asssess the utility of Model TP. In the first case study, the M\&A process was already completed and Model TP was used to conduct a post mortem on the M\&A. The Human Resources Manager, who was responsible for the people integration process, was asked to participate in the post mortem. In the second case study, the businesses were currently in the process of being integrated. The consultant advising the organisation on the merger was asked to use Model TP as the point of departure to design a project plan for the people integration process.

The overall conclusion in applying Model TP to case study one was that the model would have added value to the people integration process. It was acknowledged that the benefits of a comprehensive people integration process are underestimated in most M\&As. It was found that the newly formed business in case study one only started to perform after a full and complete business and people integration had occurred, after quite a prolonged lapse of time. The process would have benefited greatly if the people integration process was explictly and proactvely included in the overall M\&A process. The use of a comprehensive people integration process would have expedited the achievement of the expected business performance levels much earlier.

The conclusion with regard to the second case study was that a comprehensive, holistic people integration process model, like Model TP, would provide the intended M\&A with a more solid framework and sound guidelines for people integration. Addressing specific critical people success factors systematically and holistically by using the model would improve the probability of M\&A value realisation.

\section{Discussion}

As part of the research design, certain criteria for a good model were defined. In evaluating Model TP (see Figure 2) against 
these criteria, it can be concluded that Model TP complied with the criteria in the following manner:

- model TP is simple without being oversimplified

- model TP enables the description, explanation and prescription of the people integration process phenomenon; the model covers both theory and practice

- the content of the model is defined adequately, such as the building blocks, elements, relationships and the dynamics making up the model

- the model contains constant variables, such as the strategic intent of the M\&A, but also phases which represent the variable nature of the model

- the model appear to have good practical application value, although this was explored in only two case studies.

A reflection on the outcomes achieved from the comparisons of Model T, Model P and Model TP with one another, as well as the case study applications of Model TP, provided three meta-insights.

Meta-insight 1 - The gap between the espoused theory and the theory-in-action regarding the people integration process: Meta-insight 1 regarding the three-way comparisons of the three models is that building blocks making up Model $\mathrm{P}$, Model $\mathrm{T}$ and Model TP, though entitled differently in some cases, are very similar in content. This implies that the people integration process in practice and theory is seen in a highly similar way. The only major difference between the theory model (Model T) and the practice model (Model $\mathrm{P}$ ) is in the model design. Model $\mathrm{P}$ is seen more as a linear design (see Figure 1), whereas Model T and Model TP are viewed more as organic, systemic designs (see Figure 2). This indicates that, in practice, a linear approach is followed towards people integration, whereas the theory suggests an organic, systemic approach. M\&A practioners and experts, when exposed to Model T, preferred an organic, systemic design in an aspirational sense.

The conclusion drawn from this is that practitioners know the basic essentials of how to successfully integrate people during M\&As. According to Meta-insight 1, however, the espoused theory (the knowledge in practice and the literature) and the theory-in-action (the actual application) are significantly different in design - that is, how the building blocks are dynamically put together into a process of people integration. M\&A practioners and experts seemingly know what they are supposed to do, but they do not do it. he question then is: why is this the case?

Meta-insight 2 - The existence of a process within a process: The discussion of Meta-insight 1, concluding with the 'why' question, leads to Meta-insight 2. Perhaps what is missing and causing the gap between the espoused theory and theory-in-action, is the notion that one may be dealing with a process embeded within a process. The first process is the 'visible' people integration process as shown in Model TP (see Figure 2). The second 'invisible' process, that may give rise to the gap between the espoused theory and theoryin-action, is the mental model with which practioners and experts engage and apply Model TP (or any other M\&A model for that matter).
Mental models are stored pieces of information and the assumed connections between these stored pieces of information. Everyone evaluates all new information against existing information and makes new connections (Rock, 2006). People may look at the exactly same facts, but the meaning of those facts is interpreted through prior personal experiences (Covey, 2004). A mental model influences the vantage point regarding how things in reality are seen, interpreted and dealt with. A vantage point can be defined for the purpose of this article as: 'A particular personal way of thinking or set of opinions that influences the manner in which a person approaches and deals with something (Cambridge Dictionary online, 2006; Meyer, Moore \& Viljoen, 1988; Rock, 2006).

Meta-insight 2 of a process embeded within a process, where the one process relates to the people integration process (i.e. Model TP) and the mental model used as vantage point to apply the people integration process being the second process, is illustrated in Figure 3.

Arising out of Meta-insight 2 is the next question relating to the content of the mental model that needs to be chosen to close the gap between the espoused theory and theoryin-action regarding the people integration process. In other words, the choice of the right mental model as vantage point in order to engage and apply the proposed people integration process appropriately is crucial.

Meta-insight 3 - Change navigation and action learning is an essential vantage point, leveraged from the appropriate complexity perspective, to ensure a successful people integration process: Meta-insight 3 posits that if Model TP is applied from the mental model of change navigation and action learning, leveraged from the appropriate complexity perspective, the probabilty of the people integration process being successful will be significantly increased. Figure 4 illustrates this mental model as vantage point.

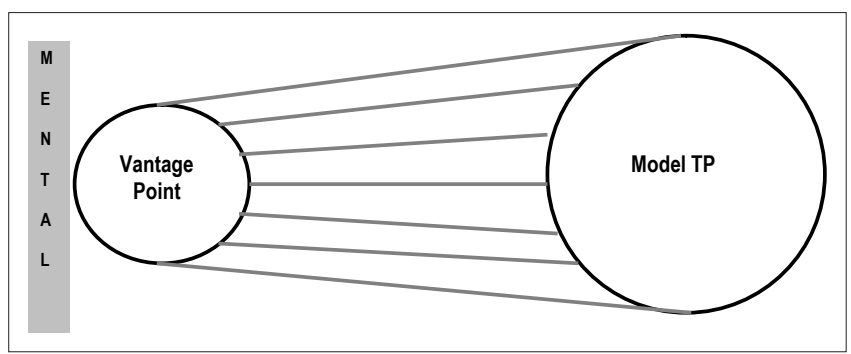

FIGURE 3: Process (Model TP) within a process (Vantage point).

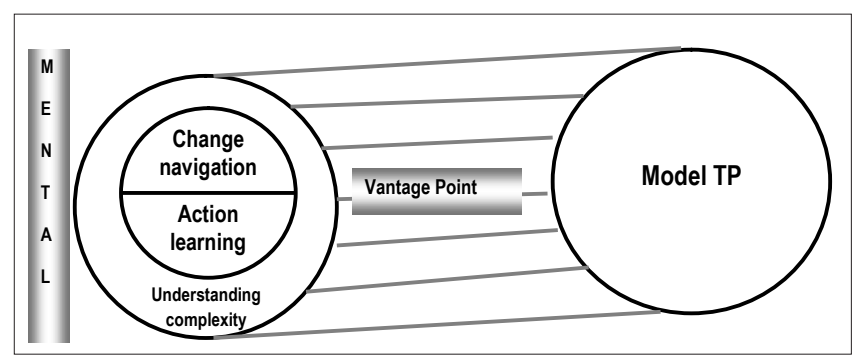

FIGURE 4: The vantage point of change navigation and action learning, leveraged from the appropriate complexity perspective. 
The contention therefore is that people integration most frequently fails (or is only partially successful), not because organisations do not have the 'right' knowledge regarding people integration (the espoused theory), but because they apply people integration (the theory-in-action) from an incorrect vantage point. The organisations concerned are, firstly, not taken through a change navigation process to buy into and take ownership of a comprehensive, holistic people integration process such as Model TP. Hence, a people integration process is merely imposed on the organisations ('dumped' probably would be a better term), which, even if it is theoretically sound, is not bought into and owned by stakeholders. The same change navigation principles as contained in Model TP are applicable here. The difference, however, in this case is that the principles of change navigation will be used to obtain upfront, pre-M\&A buy-in and ownership for adopting a model like Model TP to direct and guide the intended M\&A.

Secondly, the people integration process is typically and conventionally applied in a programmatic or project-like fashion. This linear approach contributes to an incorrect vantage point because integration teams readily succumb to a tick-off, mechanistic approach of having completed M\&A phases and steps. A tick-off, mechanistic approach suggests that the M\&A building blocks are applied sequentially. Once completed, they need not be revisited. M\&A building blocks are therefore seen as independent and not affecting one another. This approach also assumes complete knowledge and information regarding the organisations to be merged/ acquired and the responses of the organisation and its members to the unfolding M\&A process.
An organic approach, however, suggests that, because of the interconnectedness of the building blocks making up the people integration process, the respective building blocks need to be revisited several times in an iterative fashion during the M\&A integration process. Additionally, complete knowledge and information before and during the integration process do not exist. The integration process during its unfolding generates new information and knowledge on an ongoing basis, resulting from and because of the dynamic, unfolding nature of the M\&A process.

Thirdly, the M\&A integration process needs to be understood and rolled out from the right complexity perspective. The Cynefin framework distinguishes between formal and informal change conditions, as well as the interaction of both structured processes and uncertain conditions (Kurtz \& Snowden, 2003). It is divided into four domains, namely:

- 'known', where information and best practices are known and repeatable

- 'knowable', where information is not yet known, but is accessible through, for example, experts in the field

- 'complex', which focuses on emerging patterns, but where patterns from the past cannot be used to predict future patterns

- 'chaos', where the system is turbulent and there are no discernible relations.

There might be potential for order in this domain, but very few organisations can discern such order. The decisionmaking model in the chaos domain is to act quickly and decisively in order to reduce the turbulence and sense the intervention needed (Kurtz \& Snowden, 2003).

Gadiesh, Ormiston, Rovit and Critchlow (2001) depict M\&A strategic rationales on a scale from 'play by the rules'

\begin{tabular}{|c|c|c|c|c|c|}
\hline \multicolumn{3}{|c|}{ Knowable } & Complex & \multicolumn{2}{|l|}{ Chaos } \\
\hline \multicolumn{3}{|c|}{ Play by the rules } & \multicolumn{3}{|c|}{ Transform the rules } \\
\hline $\begin{array}{l}\text { Active } \\
\text { investing/ } \\
\text { Performance } \\
\text { improvement }\end{array}$ & $\begin{array}{l}\text { Growing } \\
\text { scale }\end{array}$ & $\begin{array}{l}\text { Adjacency } \\
\text { expansion }\end{array}$ & $\begin{array}{l}\text { Broadening } \\
\text { scope }\end{array}$ & $\begin{array}{l}\text { Redefining } \\
\text { business } \\
\text { models }\end{array}$ & $\begin{array}{l}\text { Redefining } \\
\text { industries }\end{array}$ \\
\hline \multicolumn{3}{|c|}{$\begin{array}{l}\text { High predictability of value } \\
\text { High functional overlap }\end{array}$} & \multicolumn{3}{|c|}{$\begin{array}{l}\text { Low predictability of value } \\
\text { Low functional overlap }\end{array}$} \\
\hline \multicolumn{2}{|c|}{$\begin{array}{l}\text { - Speed is critical } \\
\text { - } \quad \text { Focus on operational issues } \\
\text { - } \quad \text { ran actions pre-close to } \\
\text { realise } 80 \% \text { of deal value }\end{array}$} & \multicolumn{2}{|c|}{$\begin{array}{l}\text { - Sacrifice speed for most } \\
\text { strategic issues } \\
\text { - Focus equally on strategic } \\
\text { and operational issues } \\
\text { - Develop new business } \\
\text { opportunities } \\
\text { - Plan for impact on rest of } \\
\text { organisation } \\
\text { - Rationalise and cost-cut } \\
\text { where beneficial }\end{array}$} & \multicolumn{2}{|c|}{$\begin{array}{l}\text { - Sacrifice speed to get right } \\
\text { - } \text { strategic outcome } \\
\text { - } \quad \text { Socus on strategic issues } \\
\text { - } \text { improverational } \\
\text { - } \text { Retain talent } \\
\text { - } \quad \text { Cut costop strategy } \\
\text { - Create flexible action plan }\end{array}$} \\
\hline
\end{tabular}

Source: Gadiesh, O., Ormiston, C., Rovit, S., \& Critchlow, J. (2001). The 'why' and 'how' of merger success. European Business Journal, 3(2), 187-193; Kurtz, C.F., \& Snowden, D.J. (2003). The dynamics of strategy: Sense-making in a complex and complicated world. IBM Systems Journal, 42(3), 462-483. doi:10.1147/sj.423.0462

FIGURE 5: Strategic rationales and the Cynefin domains. 
to 'transform the rules'. M\&As that 'play by the rules' can be categorised into the 'known' or 'knowable' domains, whilst 'transform the rules' M\&As can be categorised in the 'complex' or 'chaos' domains. Figure 5 illustrates the contexts of M\&As in terms of strategic rationales and complexity.

Understanding complexity with respect to M\&As is important for two reasons: firstly, Figure 5 suggests that companies need to pitch their M\&A integration process from the appropriate complexity perspective before they even start the M\&A integration. Secondly, the organic, systemic nature of Model TP suggests that complete knowledge and information of the integration process do not exist and the process itself generates new knowledge and information as it unfolds. This places the application of Model TP in the complex or chaos domains, as shown in Figure 5.

A vantage point of action learning, however, provides the opportunity to navigate dynamically, in real time, the complexity and perceived 'chaos' implied by the categorisation of Model TP in the complex or chaos domains. In addition to change navigation, as one component of the vantage point, an action learning approach thus needs to be adopted in applying Model TP. Schuler and Jackson (2001) also stress the importance of learning from the M\&A process as it unfolds. A typical action learning process is illustrated in Figure 6 (Marquardt, 2004; The school for social entrepreneurs, 2006).

Using action learning as a vantage point would mean that Model TP with all its building blocks in their totality would be approached in terms of the action learning process shown in Figure 6. The integration team therefore will adopt an ongoing action learning mental model throughout the people integration process. This action learning mental model of 'diagnose and understand, plan and design, undertake action, reflect and learn, diagnose and understand' and so on, will ensure that people are successfully integrated.

Adopting an action learning approach in applying Model TP will significantly enhance the probability a successful people integration because, as and when the M\&A building blocks are activated and applied, there would be a constant, real time awareness in the organisation of what is happening in the overall organisational landscape. This will also create an ongoing awareness with regard to integration problems

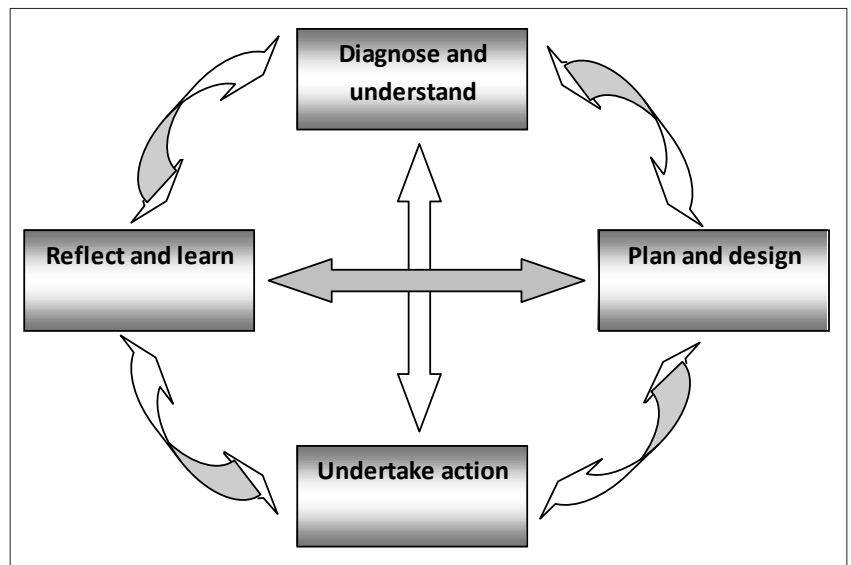

FIGURE 6: A typical action learning process. that may emerge in real time (Marquart \& Waddill, 2004). Continuous learning will take place through questioning and reflection. This will enable appropriate corrective actions and effective navigation of the 'chaos' based on real time insights. In this way the roll out of the people integration process, similar to Model TP, takes on a systemic, organic nature.

Research done on the influence of prior M\&A experience on M\&A performance further illustrates the importance of real time action learning (Galpin \& Hendon, 2007; Haleblian \& Finkelstein, 1999):

- When the current M\&A was similar to previous instances, prior experience had a positive influence.

- When the current M\&A was dissimilar to prior M\&As, prior experience had a negative influence on performance due to inappropriate generalisation errors.

- However, where organisations had prior experience and the ability to discriminate appropriately with regard to what previous knowledge to apply and when, prior experience had a positive influence, one can assume that these organisations understood the complexity and pitched the M\&A process correctly.

The last category of organisations, therefore, had the ability to learn during the MEA process.

In conclusion, Meta-insight 3 leads to the following insight: Model TP contains, in a comprehensive, holistic manner, all of the building blocks of a people integration process during M\&As (the 'what'). More importantly, however, is applying the 'what' with the right 'how' - the right mental model acting as vantage point - which would significantly enhance the chances of delivering the expected results with regard to a successful people integration and, consequently, the desired M\&A value creation and actualisation.

\section{Conclusion}

The aim of this qualitative, explorative study was to build a comprehensive, holistic people integration process model for people integration during M\&As.

It is believed that the study adds the following value to the field of M\&A's:

- Theoretical value: for the first time a comprehensive, holistic people integration process model has been developed and systematically validated by combining theory and practice. This research thus has added new theory to the existing body of knowledge regarding M\&As.

- Methodological value: the model was built by applying model design principles and sourcing inputs from experts and practitioners in the M\&A field. Both best/leading practices from practice as well as the existing literature were integrated into the model. This ensures a truly comprehensive, holistic people integration process model.

- Practical value: Model TP provides M\&A practioners and experts with guidelines on the critical building blocks, elements and the sequence making up the people integration process for successful people integration. M\&A practitioners in the M\&A field therefore now have at their 
disposal a comprehensive framework to enable them to effectively participate and contribute throughout the M\&A process.

- Organisational value: if effective people integration enhances the probability of M\&A success, most organisations will be eager to adopt a comprehensive, holistic people integration process. Such a process will enhance successful culture integration, the retention of talent, visionary leadership and other people interventions that normally contribute to successful M\&As. A successful M\&A, in return, will enhance the probability of realising the intended value of the M\&A.

- Community value: M\&A failure results in the closing down of organisations, retrenchments and the destruction of stakeholder wealth. People, their families and the wider community, not to mention shareholders, are impacted. If M\&As are handled more successfully by using this model, the broader community will benefit.

In critically reflecting on the study overall, it is believed that following strengths characterise this study: firstly, the chosen qualitative research approach which set out to understand people integration during M\&As from the perspective of best/leading practice in the first instance, followed by a theoretically generated perspective. The most important aspect of the practical side of this study was to understand people's experience of M\&As and the meaning they ascribe to this experience. The inductive approach adopted contributed towards developing new theory. It is believed that the qualitative, inductive research approach used in this particular study was the most effective research approach, given the study's problem statement. Secondly, the adopted sequence of the research phases contributed towards the study's objectivity. The practical model (Model P) was built first, followed by a literature study to build a theorical model (Model T). If the research had been conducted the other way around, the researcher could have entered the practical field with a preconceived idea of a final model. Thirdly, during the research, the context of the phenomenon was considered. Though people integration was the phenomenon studied, the phenomenon was embedded in the overall M\&A process. The proposed model is situated in the context of the overall M\&A phases (see the outer layer of Figure 2) and influencing external forces (see the outer border of Figure 2). Fourthly, the research process was designed in such a way that optimal contributions from experts and practitioners in the MEA field were solicited. Experts and practitioners in three instances (as described earlier) had the opportunity to contribute towards the final model. Fifthly, the sample of respondents came from different industries. Hence, the model has high generalisability.

The following limitations apply to the study: Firstly, the proposed Model TP is a strategic, simplified representation of the people integration process. Though the people integration process building blocks are defined and described, it is impossible to specify all of the specific variables and relationships as well as all of the detail associated with each element. The model therefore assumes a certain degree of people expert competence from the persons who will apply the model in the field. Secondly, the proposed model can be utilised with an incorrect mindset as vantage point (see Figure 4). The model appears very simple, but the wrong application mindset can cause failure. One of the metainsights arising from this study is that M\&A practioners and experts know the building blocks of people integration ('Know what to do'), but fail to implement correctly ('Do not do it'). Thus, the model is in danger of being applied mechanistically and linearly in practice, with an incorrect mindset, which will significantly heighten the probability of people integration failure. Thirdly, the model was never applied in a full scale application in a number of real life M\&As. A real life application study will truly validate the model and provide empirical results on whether the proposed process is better than the current practice.

Based on this study, two future research opportunities present themselves: firstly, applying Model TP to a real MEA process. In this study, a post mortem was done on a historical M\&A case study and a project plan was designed for an intended M\&A, using the model. These two case studies illustrated the practical use of Model TP. Applying Model TP in real, live situations may result in more insights and leanings concerning the relationships of building blocks and the complexity of people integration. Secondly, studying the mindset of practioners designing, planning and implementing a MEA process, drawing comparisons between on the one hand, successful people integration and M\&A value creation and on the other hand, a mindset of change navigation and action learning, as leveraged from the right complexity perspective. In this study, the possibility of using change navigation and action learning within the appropriate complexity perspective as a mindset to enhance the probability of applying Model TP successfully, was posited as a meta-insight but not validated. The nature and process of using change navigation and action learning mindset in conjunction with the appropriate complexity perspective to enable the success of the people integration process should be studied in depth.

Based on the final proposed people integration process model (Model TP) developed and validated in this study, organisations using M\&As as a strategy to grow will have a scientifically generated and expertly validated model for sound people integration. Applying the model from the correct vantage point will enhance the probability of M\&A success and the realisation of sustainable shareholder value, if a good deal is assumed.

\section{References}

Angwin, D., \& Savill, B. (1997). Strategic perspectives on European cross-border acquisitions: A view from top European executives. European Management Journal, 15(4), 423-435. doi:10.1016/S0263-2373(97)00021-2

Antila, E. (2006). The role of HR managers in international mergers and acquisitions: A multiple case study. International Journal of Human Resource Management, 17(6), 999-1020. doi:10.1080/09585190600693322

Antila, E., \& Kakkonen, A. (2008). Factors affecting the role of HR managers in international mergers and acquisitions. Personnel Review, 37(3), 280-299. doi:10.1108/00483480810862279

Appelbaum, S.H., Gandell, J., Yortis, H., Proper, S., \& Jobin, F. (2000). Anatomy of a merger: behaviour of organisational factors and processes throughout the pre- during- post-stages (Part 1). Management Decision, 38(9), 649-661. doi:10.1108/00251740010357267

Appelbaum, S.H., Gandell, J., Shapiro, B.T., Belisle, P., \& Hoeven, E. (2000). Anatomy of a merger: Behaviour of organisational factors and processes throughout the pre- during- post-stages (Part 2). Management Decision, 38(10), 674-684 doi:10.1108/00251740010360579 
Babbie, E., \& Babbie, E. (1992). The practice of social research. Belmont: Wadsworth Publishing Company.

Baughn, M.K., \& Finzel, P.A. (2009) A clash of cultures in a merger of two acquisition offices. Engineering Management Journal, 21(2), 11-17.

Bekier, M.M., Bogardus, A.J., \& Oldham, T. (2001). Mastering revenue growth in M\&A. McKinsey on Finance, Summer, 2001. Retrieved 2010 from http://www. mckinseyquarterly.com/Mastering_revenue_growth_in_M_A_1543

Bijlsma-Frankema, K. (2001). On managing cultural integration and culture change processes in mergers and acquisitions. Journal of European Industrial Training, 25/2/3/4, 192-207.

Boglarsky, C.A. (2005). Five steps to successful mergers and acquisitions. Human Synergistics International, printed with permission from Workspan Magazine, February 2005, http://www.humansynergistics.com

Box, G.E.P., Hunter, W.G., \& Hunter, J.S. 1978. Statistics for experimenters. An introduction to design, data analysis and model building. United States of America: John Wiley \& Sons, Inc.

Cambridge Dictionary. (2006). Vantage point. Cambridge Dictionaries online. Cambridge Advanced learner's dictionary. Cambridge University Press. Retrieved April 08, 2006 from http://dictionary.cambridge.org/define. asp?key=96287\&dict=CALD

Chapman, K. (2003) Cross-border mergers/acquisitions: A review and research agenda. Journal of Economic Geography, 3(3), 309-334. doi:10.1093/jeg/3.3.309

Child, J., Faulkner, D., \& Pitkethly, R. (2001). The management of internationa acquisitions. New York: Oxford University Press Inc.

Cilliers, F., \& Koortzen, P. (2000). The psychodynamic view on organisational behaviour. The Industrial Organisational Psychologist, 38(1), 59-67

Corporate Leadership Council. (1997). Post-merger cultural issues. Washington: Corporate Leadership Council.

Corporate Executive Board. (June, 2000). Integrating new acquisitions: The case of Cisco Systems. Washington: Corporate Executive Board.

Corporate Leadership Council. (1999). The role of HR in mergers and acquisitions. Washington: Corporate Leadership Council.

Covey, S.R. (2004). The 8th Habit. London: Simon \& Schuster UK Ltd.

Cummings, T.G., \& Worley, C.G. (2001). Organisation development and change. Ohio: South-Western College Publishing.

Czander, W.M. (1993). The psychodynamics of work and organisations. New York/ London: Guilford Press.

De Vos, A.S., Strydom, H., Fouche, C.B., \& Delport C.S.L. (2002). Research at grass roots for the social sciences and the human resources professionals. Pretoria:Van roots for the socia
Schaik Publishers.

Deans, G.K., Kroegler, F., \& Zeisel, S. (2003). Winning the merger end game. New York: CWL Publishing Enterprises.

Deeprose, D. (2003). Smart things to know about culture. Oxford: Capstone Publishing Limited.

Devoge, S. \& Shiraki, J. (2000) People factors: The missing link in merger success. Compensation \& Benefits Management, Winter 2000, 26-32.

Eisenhardt, K.M. (1989). Building theories from case study research. The Academy of Management Review, 14(4), 532-550. doi:10.2307/258557

Epstein, M.J. (2005). The determinants and evaluation of merger success. Business Horizons, 48(1), 37-46. doi:10.1016/j.bushor.2004.10.001

Evans, P., Pucik V., \& Barsoux, J. (2002). The global challenge. Frameworks for international human resource management. New York: McGraw-Hill/Irwin.

Ficery, K., Herd, T., \& Pursche, B. (2007). Where has all the synergy gone? The M\&A puzzle. Journal of Business Strategy, 28(5), 29-35. doi:10.1108/02756660710820802

Firth, D. (2000). Smart things to know about change. Oxford: Capstone Publishing Limited.

French, W.L. \& Bell, Jr. C.H. (1999) Organisation Development. (Sixth edition). Behavioural science interventions for organisational improvement. New Jersey: Prentice Hall.

Gadiesh, O., Ormiston, C., Rovit, S., \& Critchlow, J. (2001). The 'why' and 'how' of merger success. European Business Journal, 3(2), 187-193.

Galpin, T.J. \& Herndon, M. (2007) The complete guide to mergers and acquisitions. (2nd Edition). San Francisco: Jossey-Bass.

GIBS (2006). Mergers and acquisitions: South Africa and beyond. Finweek, 18 May 2006, 53-53.

Gillingham, A. (2006). SA exceeds global average with $62,5 \%$ growth in deals. 11 April, Seminar Handout at BIOSS SA Seminar (2006) in Johannesburg.

Greiner, L., \& Poulfelt, F. (2005). The contemporary consultant. South Western: Thomson.

Grundy, T. (2003). Smart things to know about mergers and acquisitions. Oxford: Capstone Publishing Ltd.

Haleblian, J., \& Finkelstain, S. (1999). The influence of organisational acquisition experience on acquisition performance: A behavioural learning perspective. experience on acquisition performance: A behavioural learning
Administrative Science Quarterly, 44, 29-56. doi:10.2307/2667030

Haspeslagh, P.C., \& Jemison, D.B. (1991). Managing acquisitions. Creating value through corporate renewal. New York: The Free Press, a Division of Macmillan, Inc.
Hitt, M.A., Harrison, J.S., \& Ireland, R.D. (2001). Mergers and acquisitions. A guide to creating value for stakeholders. New York: Oxford University Press, Inc.

Human Synergistics. (2000). Leadership/Impact ${ }^{\oplus}$. Facilitators Guide. Center for Applied Research, Inc.

Ing, L. (2000). Playing the merger and acquisition game: a people centred approach Johannesburg: Presentation at BIOSS SA Seminar (2006) in Johannesburg.

Interchange International Inc. (2001). The Inter Change Cycle ${ }^{T M}$. Participant's guide. Hillcrest, South Africa.

Kale, P., Singh, H., \& Raman, A. (2009). Don't integrate your acquisitions, partner with them. Harvard business review, December 2009, 109-115.

Kanter, R. M. (2003). Leadership and the psychology of turnarounds. Harvard Business Review, June, 81(6), 58-67.

Kelly, J., Cook, C., \& Spitzer, D. (1999). Mergers and acquisitions: A global research report. (Unlocking shareholder value: the keys to success), a study by KPMG. London.

Kotter, J.P. (1996). Leading change. Boston: Harvard Business School Press.

Kummer, C. (2008). Using HR metrics to make mergers and acquisitions a success. Strategic HR review, 7(4), 39-48.

Kurtz, C.F., \& Snowden, D.J. (2003). The dynamics of strategy: Sense-making in a complex and complicated world. IBM Systems Journal, 42(3), 462-483. a complex and complic
doi:10.1147/sj.423.0462

Mafu, T. (2006, 5 April). Corporate deals up R103bn in 2005. South Africa's National Financial Daily, Business Report.

Marks, M.L., \& Mirvis, P.H. (1998). Joining forces. Making one plus one equal three in mergers, acquisitions and alliances. San Francisco: Jossey-Bass Publishers.

Marquardt, M.J. (2004). Action learning. A powerful new tool for developing individuals, teams and organisations. BY GEORGE! The George Washington University Faculty, Staff and Community Newspaper. Feb. 18, 2004 doi:10.1080/1476733042000264146

Marquardt, M.J., \& Waddill, D. (2004). The power of learning in action learning: a conceptual analysis of how the five schools of adult learning theories are incorporated within the practice of action learning. Action learning: Research and Practice, 1(2), 185-202.

McNamara, C. (1999). Basic overview of various strategic planning models. Retrieved December 12, 2005 from http://www.mapnp.org/library/plan_dec/str_plan/ models.htm

Meredith, D.D., Wong, K.W., Woodhead, R.W., \& Wortman, R.H. (1985). Design and planning of engineering systems. New Jersey: Prentice-Hall, Inc.

Meyer, W.F., Moore, C., \& Viljoen, H.G. (1988). Persoonlikheidsteorieë van Freud tot Frankl. Kaap: Lexicon Uitgewers (Eiendoms) Beperk.

Miles, M.B., \& Huberman, A.M. (1994). An expanded sources book of qualitative dato analysis. California: SAGE Publications, Inc.

Mittner, M. (2006, 10 March). Standard cuts international teeth. Beeld, n.p.

Morgan, M.S., \& Morris, M. (1999). Models as mediators. Perspectives on natural and social science. Cambridge: Cambridge University Press. doi:10.1017/ CBO9780511660108

Mouton, J. (1996). Understanding social research. Pretoria: J.L. van Schaik Publishers.

Neuman, W.L. (2003). Social research methods: Qualitative and quantitative approaches. Boston: Allyn and Bacon.

O'Reilly, C.A., \& Pfeffer, J. (2000). Hidden value. How great companies achieve extraordinary results with ordinary people. Boston, Massachusetts: Harvard Business School Press.

Pritchett, P. (1996). Making mergers work. A guide to managing mergers and acquisitions. USA: Pritchett \& Associates, Inc.

Rock, D. (2006). Quiet leadership. New York: HarperCollins Publishers.

Rock, M.L., Rock, R.H., \& Sikora, M. (1994). The mergers and acquisitions handbook. Massachusetts: McGraw-Hill, Inc.

Sarlitto, M., \& Roman, D. (2006). An introduction to operations due diligence. KeiretsuNews, Your Quarterly Newsletter, January, 1-3.

Schein, E.H. (1986). What you need to know about organisational culture. Boston, Training and Development Journal, 40(1), 30-31.

Schurink, W.J. (2003). The manual on qualitative models in the leadership in performance and change programme. Johannesburg: RAU class notes.

Schuler, R., \& Jackson, S. (2001). HR issues and activities in mergers and acquisitions. European Management Journal, 19(3), 239-253. doi:10.1016/S02632373(01)00021-4

Senge, P.M. (1990). The fifth discipline. The art and practice of the learning organisation. New York: Currency Doubleday, Division of Bantam Doubleday Dell Publishing Group, Inc.

Seo, M., \& Hill, N. S. (2005). Understanding the human side of merger and acquisition An integrative framework. The Journal of Applied Behavioural Science, 41(4), 422-443. doi:10.1177/0021886305281902

Sherman, A.J. ( 1998). Mergers and acquisitions from A to Z: Strategic and practical guidance for small-and middle-market buyers and sellers. New York: AMACOM.

Lambert, S.D. (1999). The transformation of British Airways World Cargo. Article and Video London.

Snowden, D.J. (2003). Complex acts of knowing: Paradox and descriptive selfawareness. Special Edition Journal of Knowledge Management. 6(2), 100-111. doi:10.1108/13673270210424639 
Statistics South Africa. (2006) Statistical release PO 441 2nd Quarter 2006 Retrieved June 24, 2006 from http://www.statssa.gov.za/PublicationsHTML/ Retrieved June 24, 2006 from
PO4412ndQuarter2006/html

Tanure, B., \& Gonzalez-Duarte, R. (2007). Managing people in radical changes (M\&As). International Journal of Manpower, 28(5), 369-383. doi:10.1108/01437720710778376

Tayser, D. (2010). Personal communication. Johannesburg: Ernstand Young.

The Economist. (2006). Mergers and acquisitions. Once more unto the breach, dear clients, once more. 379 (8472), 08 April, 73 \& 74.

The School for Social Entrepreneurs. (2006). Why action learning? Retrieved March 28, 2006 from http://www.sse.org.uk/network/learning/why_action_learning. shtm

Towers Perrin (2000). Merger and acquisition issues. Article by Towers Perrin Consulting Firm: Johannesburg.

Veldsman, T.H. (2002). Into the people effectiveness arena: Navigating between chaos and order. Randburg: Knowledge Resources.
Vinassa, A. (2003). See it, feel it, change it. People Dynamics, 21(2), 14-15.

Visser, A. (2006). Sasol does not appeal because of protracted uncertainty. Beeld, Dinsdag 14 Maart, 2006.

Weaver, T., Keys, B., \& Tayser, D. (2008). Mergers \& Acquisitions: A review of activity for the year 2007. Johannesburg: Ernst \& Young.

Welman, J.C., \& Kruger, S.J. (1999). Research methodology for the business and administrative sciences. Cape Town: Oxford University Press.

West, T.L., \& Jones, J.D. (1997). Mergers and acquisitions handbook for small and midsize companies. USA: John Wiley and Sons, Inc.

Wickramasinghe, V., \& Karunaratne, C. (2009). People management in mergers and acquisitions in Sri Lanka: employee perceptions. The International Journal of Human Resource Management, 20(3), 694-715. doi:10.1080/09585190802707508

Zou, H., \& Simpson, P. (2008). Cross-border mergers and acquisitions in China: An industry panel study, 1991-2005. Asia Pacific Business Review, 14(4), 491-512. doi:10.1080/13602380701437460 